months) and $(6.31 \pm 1.75 \mathrm{~kg})$ respectively. The age and weight in group B was (7.6 \pm 3.9 months) and $(4.84 \pm 1.12) \mathrm{kg}$ respectively. There were no significant differences between the 2 groups in term of post operative mortality or morbidity.

Conclusion Failure to thrive can complicate congenital heart diseases (CHD) associated with significant left to right shunt and heart failure. FTT was not associated with increase in ICU morbidity or mortality. Attempt to optimize the body weight for age in children with CHD may not add any beneficial advantages in term of surgical risk or postoperative ICU outcome.

\section{OUTCOMES OF PEDIATRIC TETANUS IN WESTERN INDIA}

doi:10.1136/archdischild-2012-302724.0804

'W Shukla, ${ }^{1}$ AS Nimbalkar, ${ }^{1,2}$ SM Nimbalkar. ${ }^{1}$ Department of Pediatrics, Pramukhswami Medical College; ${ }^{2}$ Central Research Services, Charutar Arogya Mandal, Anand, India

Background Despite being easily preventable with a highly effective vaccine, tetanus remains a significant source of morbidity and mortality. We determined the clinical profile and outcome of management of paediatric tetanus admitted to our tertiary care hospital over 7 years.

Methods Retrospective chart evaluation of all patients admitted from 2005 to 2012 between age groups of 1 month and 18 years. Demographic and Clinical Profile, Management in the hospital and variables affecting outcomes were studied.

Results 65 patients (43 males, 22 girls) were admitted. Average age was 8.4 years. 12 children died, 32 discharged while 21 were transferred to another facility. 24/65 were unvaccinated, 21/65 partially vaccinated and 10 received proper immunization. Average incubation period (IP) was 7 days with patients with otogenic tetanus having IP of 15 days. 19 patients were ventilated for average duration of 5.74 days while 18 required tracheotomy. 25 patients had laryngeal spasms and 7 had autonomic instability. 14 patients did not receive Tetanus Immunoglobulin (TIG) while 51 received TIG in various forms (intrathecal, intramuscular or both). 5 patients who received only intrathecal survived while 13 of 19 that received both survived. $3 / 27$ who received intramuscular tetanus died and 3/14 who received no TIG died. Odd Ratio for Death in No TIG use vs TIG use was 1.16 (CI 0.26.6, 5.3)

Conclusions Tetanus is prevalent in India and causes significant morbidity and mortality. $27.3 \%$ mortality shows that treating tetanus is still difficult. Use of intrathecal TIG was not associated with a beneficial effect.

\section{PROSPECTIVE OBSERVATIONAL STUDY OF COMPLICATIONS OF CENTRAL VENOUS CATHETERISATION IN A REGIONAL PAEDIATRIC INTENSIVE CARE UNIT}

doi:10.1136/archdischild-2012-302724.0805

H Gowda, C Penrose. Paediatric Intensive Care Unit, Leeds Teaching Hospitals NHS Trust, Leeds, UK

Background and Aims Central Venous Cather (CVC) has become an indispensable route for venous access in Paediatric Intensive Care Units(PICU). Used worldwide to monitor haemodynamic status, administer fluids, medication, parenteral nutrition and for blood sampling.

To evaluate various complication rates of triple lumen CVC in PICU.

To investigate the relationship between the duration of percutaneous central venous catheterisation and the occurrence of catheter-related complications.

Methods A prospective study (August 2010 to July 2011) of 227 central venous catheterisations in children of different ages in a regional PICU. Data on demography, site of insertion, complications during insertion and complications during line in-situ were collected.
Results Total number of CVC days (for 227 CVC) was 960 days.

Complications during insertion were multiple attempts(4.84\%), bleeding $(0.88 \%)$ and haemothorax $(0.44 \%)$.

Abstract 805 Table 1 Central venous catheter complication rates

\begin{tabular}{llll}
\hline Type of complication & Infection & Thrombosis & Leakage \\
\hline Complication rates & $\begin{array}{l}22.91 \text { per } 1000 \\
\text { catheter days }\end{array}$ & $\begin{array}{l}4.16 \text { per } 1000 \text { catheter } \\
\text { days }\end{array}$ & $\begin{array}{l}18.75 \text { per } 1000 \\
\text { catheter days }\end{array}$ \\
\hline
\end{tabular}

Abstract 805 Table 2 Complication in relation to duration of CVC

\begin{tabular}{lccc}
\hline Type of complication & $\begin{array}{c}\text { Number of } \\
\text { catheters }\end{array}$ & $\begin{array}{c}\text { Total catheter } \\
\text { days }\end{array}$ & $\begin{array}{c}\text { Average duration of one CVC } \\
\text { in-situ in days }\end{array}$ \\
\hline Infection & 22 & 188 & 8.54 \\
Leakage & 17 & 129 & 7.5 \\
Thrombosis & 4 & 14 & 3.5 \\
No complications & 177 & 629 & 3.55 \\
\hline
\end{tabular}

Abstract 805 Table 3 Internal jugular vein vs femoral vein

\begin{tabular}{lccc}
\hline & Internal jugular vein & Femoral vein & Relative risk \\
\hline CVC infection & $11 / 127(8.66 \%)$ & $11 / 90(12.22 \%)$ & 1.4 \\
\hline
\end{tabular}

Conclusion Overall complication rates of CVC is 45 per 1000 catheter days.

Infectious complications were independent of the venous access site, but increases with the duration of catheterisation. Thrombotic complications happened within short period of catheterisation

\section{ARTERIAL OXYGEN TENSION AND OUTCOME AFTER OUT- OF-HOSPITAL CARDIAC ARREST IN CHILDREN}

doi:10.1136/archdischild-2012-302724.0806

${ }^{1} \mathrm{HK}$ Kanthimathinathan, ${ }^{1}{ }^{2} \mathrm{~B}$ S Scholefield, ${ }^{3} \mathrm{~S}$ Raman, ${ }^{3} \mathrm{~A}$ Hussey, ${ }^{4} \mathrm{~F}$ Haigh, ${ }^{3} \mathrm{~S}$ Skellet, ${ }^{1} \mathrm{H}$ Duncan, ${ }^{3} \mathrm{M}$ Peters, ${ }^{1} \mathrm{~K}$ Morris. ${ }^{1}$ Paediatric Intensive Care Unit, Birmingham Children's Hospital NHS Trust, Birmingham; '2Medical School, University of Warwick, Warwick; ${ }^{3}$ Paediatric Intensive Care Unit, Great Ormond Street Hospital, London; ${ }^{4}$ Paediatric Intensive Care Unit, Alder Hey Children's Hospital, Liverpool, UK

Background There is good evidence that hyperoxia after resuscitation in the newborn period can be detrimental to neurological outcome and survival. The association between hyperoxia and survival after out-of-hospital cardiac arrest (OHCA) in children has not been evaluated.

Methods A retrospective, observational study of children admitted to 3 PICUs after OHCA (2004-2010). Primary outcome was survival to hospital discharge. Patients were divided into three groups (hypoxia $<8 \mathrm{kPa}$, normoxia $8-40 \mathrm{kPa}$, hyperoxia $>40 \mathrm{kPa}$ ) based on arterial oxygen tension in the first 24 hours. The $\mathrm{PaO}_{2}$ thresholds used are based on recently published literature.

Results 140 patients were identified (51 hypoxia, 60 normoxia, 29 hyperoxia), with the hyperoxia group significantly older than other groups (Table). The predicted probability of death (PIM2) at PICU admission was similar across the three groups, as was the use of interventions, such as transfer between hospitals and requirement for inotropes. Survival to hospital discharge was only $14 \%$ (95\% CI: $4-31$ ) in the hyperoxia group against $27 \%$ (95\% CI: $16-40)$ in the normoxia group and 37\% (95\% CI: 24-52) in the hypoxia group ( $p=0.08)$. The Odds Ratio for survival in the hyperoxia group was 0.44 ( $95 \% \mathrm{CI}: 0.13-1.46, \mathrm{p}=0.18)$ compared to the normoxia group. 


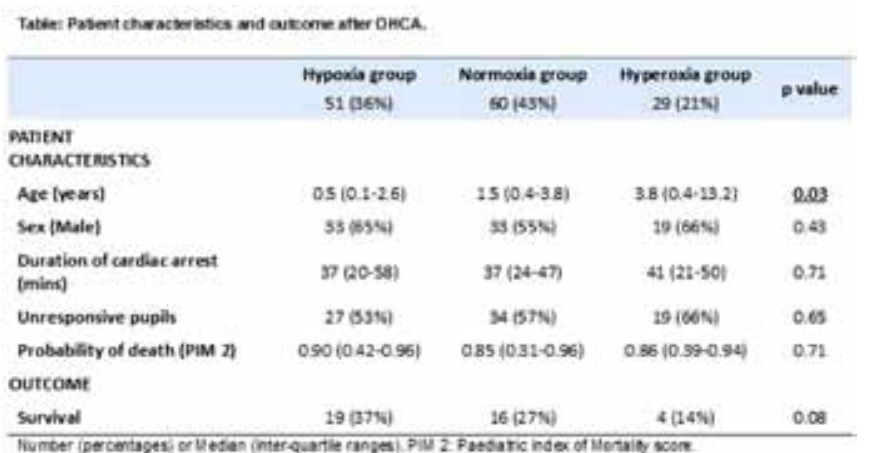

Conclusions This study has observed a difference in survival related to oxygen tension status, with a trend to worsening survival from hypoxia through to hyperoxia. Confirmation of this preliminary finding is required in a larger cohort before embarking on a randomised controlled trial.

\section{HYPOCORTISOLEMIA IN SICK CHILDREN ON PAEDIATRIC INTENSIVE CARE UNIT (PICU): TRANSIENT OR CAUSE FOR CONCERN}

doi:10.1136/archdischild-2012-302724.0807

${ }^{1} \mathrm{H}$ Bentur, 'S Mahoney, ${ }^{2} \mathrm{~J}$ Blair. 'Paediatric Intensive Care; ${ }^{2}$ Paediatric Endocrine, AlderHey Children's NHS Foundation Trust, Liverpool, UK

Background and Aims Cortisol insufficiency has been reported in sick children with severe sepsis, post-cardiac surgery, and may contribute to rapid cardiovascular collapse. Hypothalamic-pituitaryadrenal axis dysfunction may play a role in low-cardiac-output syndrome. We performed a review of PICU patients to describe cortisol levels in those with suspected adrenal insufficiency.

Methods Retrospective review of PICU patients (general and cardiac cases) over 6 months from April to September 2011, who had cortisol levels checked and/or received hydrocortisone.

Results Total PICU admissions were 519, of which $30(5.7 \%)$ patients had cortisol levels. Most common indication for cortisol assessment was refractory hypotension (73\%) in cardiac and sepsis patients. $12 / 30(40 \%$ ) had cortisol levels $<500 \mathrm{nmol} / \mathrm{L}$ (suboptimal response to stress), and $2 / 12$ had undetectable cortisol levels. Of 12 with low cortisol, $50 \%$ were post-operative cardiac neonates and $50 \%$ were mix of other post-operative and chronic illness, $75 \%$ were hypotensive on inotropes and one-third of these received hydrocortisone in PICU. Hydrocortisone dose used was variable. None of the septic children had low cortisol in our study group. $50 \%$ of hypocortisolemia patients were followed up by endocrine team and had normal cortisol levels on follow-up. 10/30(33\%) patients with suspected adrenal insufficiency died (50\% had hypocortisolemia).

Conclusions Our data shows that hypocortisolemia can be transient in sick PICU patients, and may play a role in low-cardiac-output syndrome. There is a need to identify these complex patients with high mortality, and have a uniform management policy jointly with advice and follow-up by the Endocrine team.

\section{UNPLANNED READMISSION TO THE PAEDIATRIC INTENSIVE CARE UNIT (PICU). CAN IT BE PREVENTED?}

doi:10.1136/archdischild-2012-302724.0808

D White, H Coscrato Bachmayr. Paediatric Intensive Care Unit, Cambridge University Hospitals NHS Foundation Trust, Cambridge, UK

Background and Aims It is known that patients readmitted to the PICU during the same hospitalization have significantly adverse outcomes ${ }^{1}$. Prevention of unplanned readmissions to the Paediatric
Intensive Care Unit (PICU) is a key factor when considering the quality of care received by our patients.

Methods All admissions to the PICU during 2011 were examined and all readmissions to the unit were identified. A readmission was defined as those requiring PICU $<48$ hours following discharge. Patients who were readmitted for an elective procedure within the specified time were discounted.

Results During 2011, 511 children had 615admissions to the PICU. 12 children were readmitted for acute care having deteriorated in the ward setting. 2 of the 12 children required 2 readmissions. 5 of the readmissions took place between April and September. The remaining 9 occurred during October to March.

Conclusions It remains a subject of debate as to whether or not any of the redamissions could have been avoided as hindsight is always easy. With nearly double the amount readmissions occuring during the winter months, it could be argued that the children were discharged prematurely due to bed pressures. This a serious concern and one which we will continue to monitor.

1. Odetola et al 2007 Pediat Crit Care Med. Going back for More.

\section{PROSPECTIVE STUDY OF PEDIATRIC CARDIAC ARREST IN EUROPEAN AND LATINOAMERICAN INTENSIVE CARE UNITS}

doi:10.1136/archdischild-2012-302724.0809

1.2 J del Castillo Peral, ${ }^{3} \mathrm{~J}$ López-Herce, European Latinoamerican Study Group of Cardiac Arrest in Children. 'Servicio de Cuidados Intensivos Pediátricos, Hospital General Universitario Gregorio Marañón; ${ }^{2}$ Red Iberoaemericana de Estudio de la Parada Cardiaca en la Infancia; ${ }^{3}$ Hospital General Universitario Gregorio Marañón, Madrid, Spain

Objective To study the characteristics of cardiac arrest (CA) and the results of resuscitation in pediatric intensive care units (PICU).

Patients and methods: Prospective, international, multicentrical study. Children between 1 month and 18 years who suffered CA in the PICU were included. Sustained return of spontaneous circulation (ROSC) and survival at hospital discharge were analyzed.

Results 304 CA episodes in 250 patients were registered, 96 $(31.6 \%)$ in latinoamerican and $208(68.4 \%)$ in European hospitals. Mean age was 47.9 months, mean weight $16.4 \mathrm{~kg}$ and $55.6 \%$ males. The most common causes of CA were cardiac (35.9\%), respiratory $(31.6 \%)$ and sepsis (15.3\%). ROSC was attained in $68.1 \%$ of the cases but only $40.4 \%$ survived. ROSC was higher in European $75.9 \%$ than in Latinamerican 55.4\% PICUs $(\mathrm{p}=0.001)$. Patients with good neurological scales before CA (PCPC $<=2$ ) had significantly higher ROSC rates (74.5\% vs $33.3 \%$; $=0.006)$. Patients who had suffered a previous CA had lower ROSC percentages ( $51.7 \%$ vs $71.1 \%$; $\mathrm{p}=0.03$ ). Respiratory and cardiac CA have higher survival rates $(40 \%$ and $56.3 \%)$ than sepsis (13.5\%), and neurologic and traumatic causes $(31.7 \%)(p<0.001)$. Initial respiratory arrests achieved higher survival rates than primary CA ( $49 \%$ vs $35.1 \%$; $p=0.029$ ). Patients previously receiving inotropic drugs survived less than those who received no medication ( $31.3 \%$ vs $58 \%$; p $<0.001$ ).

Conclusions Although $68 \%$ of patients who suffered a CA attained ROSC only $40 \%$ of them survived. Ethiology of CA, type of initial arrest and previous treatment with inotropics influence survival in PICU cardiac arrest.

\section{MORBIDITY AND MORTALITY IN CRITICALLY ILL CHILDREN WITH SPONTANEOUS INTRACEREBRAL HEMORRHAGE}

doi:10.1136/archdischild-2012-302724.0810

S Stabouli, A Violaki, E Volakli, S Kalamitsou, M Kotsiou, M Sdougka. PICU, Hippokration Hospital, Thessaloniki, Greece

Background and Aims Spontaneous intracerebral hemorrhage (ICH) accounts for approximately half of stroke in childhood with 